\title{
Till the ocean do us part: Italian and American therapists' representations of stepfamilies in treatment
}

\author{
Monica Accordini, ${ }^{1}$ Scott Browning, ${ }^{2}$ Marialuisa Gennari, ${ }^{1}$ Kevin McCarthy, ${ }^{2}$ Davide Margola ${ }^{1}$ \\ ${ }^{1}$ Catholic University of Milan, Italy; ${ }^{2}$ Chestnut Hill College, Philadelphia, PA, USA
}

\begin{abstract}
Research often focuses on the characteristics of stepfamilies and their differences with first-union families; however, few studies take into account the therapist's perspective with regards to the treatment of such families. Also, cross-cultural research on the topic is limited. To fill these gaps, a content analysis of responses from 125 Italian and 45 American therapists regarding their representations of stepfamilies and stepfamily therapy was undertaken. Results show that American therapists emphasized specific stepfamily characteristics (e.g., the lack of a shared family history, the occurrence of conflict between former spouses, the presence of unrealistic expectations towards treatment) to a greater extent if compared to Italian therapists. By contrast, besides being more general in their definition of stepfamilies, Italian therapists focused more on themselves, their theoretical models, and their professional and personal skills. The study provides insights on both the differences in the clinical cultures of the two countries and implications for stepfamily therapy and training.
\end{abstract}

Key words: Content analysis; Cross-cultural differences; Stepfamilies; Stepfamily therapy; Therapist attitudes.

\section{Introduction}

Therapists are expected to be culturally competent (DeAngelis, 2015) by demonstrating sensitivity to differences in clients, such as those associated with race and ethnicity, gender and sexual orientation, and social class. Therapists who work with families have the additional

Correspondence: Monica Accordini, Faculty of Psychology, Catholic University of Milan, Largo A. Gemelli 1, Milan, MI 20123, Italy.

E-mail: monica.accordini@unicatt.it

Citation: Accordini, M., Browning, S., Gennari, M., McCarthy, K., \& Margola, D. (2017). Till the ocean do us part: Italian and American therapists' representations of stepfamilies in treatment. Research in Psychotherapy: Psychopathology, Process and Outcome, 20(3), 187-200. doi: 10.4081/ripppo.2017.271

Acknowledgements: We would like to thank Professor Beatrice K. Pasley for her help and insightful comments on the first draft of this paper.

Received for publication: 2 May 2017.

Revision received: 3 August 2017.

Accepted for publication: 4 September 2017.

This work is licensed under a Creative Commons Attribution NonCommercial 4.0 License (CC BY-NC 4.0).

CCopyright M. Accordini et al., 2017

Licensee PAGEPress, Italy

Research in Psychotherapy:

Psychopathology, Process and Outcome 2017; 20:187-200

doi:10.4081/ripppo.2017.271 challenge of demonstrating cultural competences in their work with complex family forms (e.g., stepfamilies, cohabiting couples). One aspect of multicultural competence includes awareness of both one's own and the client's representations and beliefs (Altmaier \& Hansen, 2011) together with the ability to understand and adequately respond to client expectations in therapy. The concept of therapists' representations is particularly important as clinicians form their idea of the client based on their own conceptualization of reality (Rogers, 1983), which, in turn, is influenced by their knowledge of the client, their own theoretical background and training received, their expectations as well as by other context and situational factors (Higgs, Jones, Loftus, \& Christensen, 2008). In other words, therapists' perceptions of stepfamilies and their educational and training experiences are inevitably interwoven.

To date, research on the therapists' representations of stepfamilies is scarce to non-existing, and this is surprising especially if we consider: (1) the increasing number of stepfamilies and repartnerships in many countries (ISTAT, 2015; U.S. Census Bureau, 2012; Vikat et al., 2007); (2) the correlation between non-specific therapeutic variables (e.g., the therapists' attitude towards the client and his/her cultural background) and positive treatment outcomes (Beutler, Machado \& Nenfelt, 1994; Elliott et al., 2011); (3) the higher number of dropouts of minority clients in general (Altmaier \& Hansen, 2011) and stepfamily members in particular (Ford \& Hecker, 2008; Pasley, Rhoden, Visher, \& Visher, 1996) due to the therapist's inexperience, lack of awareness or sensitivity towards their particular situation and life context; (4) the fact that therapists' representations and beliefs inform their clinical reasoning and therefore shape the therapist- 
patient communication as well as the therapeutic actions undertaken (Higgs et al., 2008); (5) the comparison between therapists' perceptions and research findings might provide useful information on the extent to which the latter have filtered down (Fisher \& Sprenkle, 1978) and are actually applied in everyday practice.

Moreover, while several studies have focused on the cultural and national differences in marriage and family therapy (Hardy \& Laszloffy, 1995; McDowell, Goessling, $\&$ Melendez, 2012) and, more recently, some attention has addressed the manner in which family therapists are trained and practice in various countries (Dattilio, Piercy, \& Davis, 2014; Piercy et al., 2014), there's only one study investigating the representations of stepfamilies in a sample of Italian therapists (Browning, Accordini, Gennari, \& Cigoli, 2010) while no cross-cultural studies have been published on the topic.

The present paper adds to the literature on stepfamily therapy by focusing on clinicians in two countries (Italy and the U.S.) where similar theoretical orientations exist, but where virtually no research exists that addresses their representations about stepfamilies and how such representations influence their cultural competence in their work. More specifically, the goal of the present study is twofold: (1) to examine how the Italian and American therapists in our sample perceive stepfamilies and their practice with this kind of clients, and (2) to compare the representations of the Italian and American clinicians in an attempt to understand how the two groups might inform one another, while drawing some implications for practice in the two cultural contexts.

\section{Stepfamilies in Italy and the U.S.}

Although stepfamilies are not a new family form, their numbers continue to grow with the U.S. having the highest number of stepfamilies following marital disruption (Sweeny, 2010; U.S. Census Bureau, 2012). America is not alone in this pattern, as most European countries have experienced an exponential increase in stepfamilies, although this is primarily due to the rise in divorce and remarriage rates (Fürnkranz-Prskawetz, Vikat, Philipov, \& Engelhardt, 2003; Vikat et al., 2007). Although Italian stepfamilies are not as common as U.S. stepfamilies, they are becoming more widespread (Bianca, Malagoli Togliatti, \& Micci, 2005; Mazzoni, 2002). With the 89,303 separations and the 52,335 divorces that occurred in 2014, relationship dissolution has increased. For example, marriages ending by their 10th anniversary increased from $4.5 \%$ in 1985 to $11 \%$ in 2005 , and many of these spouses have children: $76.2 \%$ of separating and $65.4 \%$ of divorcing couples in 2014 had one or more child(ren). Other data show that the ratio of second to first marriages increased, growing from $12.8 \%$ in 2008 to $16.1 \%$ in 2014 (ISTAT, 2015), and the most recent data (2009) show that stepcouples (either remarried or cohabiting) were $7 \%$ of the overall population. In $37.9 \%$ of cases both partners had children from previous unions, whereas in $12.9 \%$ of cases both spouses had their own children and a mutual child (ISTAT, 2011).

With regards the U.S., Lewis and Kreider (2015) report that $42 \%$ of all recent marriages are remarriages for one or both partners, and the Pew Research Center (2011) records show that in America $42 \%$ of the adult population 18 years and older is in a step relationship, being either a stepparent, stepchildren, or stepsibling. According to Livingston (2014), 42 million people are remarried in America and another 36 million are either divorced or widowed, so logically 78 million Americans are already, or could potentially become, part of a stepfamily. Much of these data use an outdated definition of stepfamily based on remarriage, failing to consider nonresident stepfamilies (a stepfamily in which the child visits), cohabiting stepfamilies, and first marriage stepfamilies, leading to underestimating the actual number of stepfamily households.

While they are reported to be growing in number both countries, Italian and American stepfamilies bear significant differences, especially with regards to the age of the partners at the time of the family formation (with Italians repartnering at later age) and the presence of young cohabiting stepchildren (with only $4 \%$ of Italian stepchildren being 18 or younger) (Fürnkranz-Prskawetz et al., 2003; Steinbach, Kuhnt, \& Knüll, 2016). Moreover, generally speaking, the Italian population is more homogeneous in terms of race and religion if compared to the American, and this applies to both stepfamily members and therapists alike.

While these differences are to be kept into account in making cross-national comparisons, studies have shown that both American and European families are subject to the nuclear family ideology (Ganong \& Coleman, 2016) and are largely influenced by the same myths, beliefs, and stigmatization (Kreyenfeld \& Heintz-Martin, 2011).

\section{Clinical interventions with stepfamilies}

Research on stepfamilies in general in the U.S. has a long and rich history as noted in the decade reviews in the Journal of Marriage and Family (see, respectively, PriceBonham \& Balswick, 1980; Coleman \& Ganong, 1990; Coleman, Ganong, \& Fine, 2000; Sweeny, 2010). The exposure to models of treating the specific issues raised in stepfamilies has occurred in the U.S. since the late 70's (see Browing \& Artelt, 2012; Papernow, 2015; Visher \& Visher, 1998). For therapists not educated in the specific dilemmas and problems faced by stepfamily members, scholars suggest that their therapeutic interventions may be poorly designed for these families (e.g., Browning \& Bray, 2009; Gurman, 2008). Moreover, trying to assess and treat stepfamily problems using traditional family therapy approaches often leads to client dropout (Ford \& Hecker, 2008; Pasley, Rhoden, Visher, \& Visher, 1996) and dissatisfaction with treatment (Higginbotham \& Adler-Baeder, 2008). Despite the increasing number of 
stepfamilies in all Western countries (FürnkranzPrskawetz et al., 2003; Kreyenfeld \& Heintz-Martin, 2011), few publications address the specific issues and techniques to be used in stepfamily therapy.

While stepfamily members usually expect their life to mirror that of first-union families and try to enact the same types of boundaries, roles, rules, discipline, and/or relationships (see Ganong \& Coleman, 2016), there are crucial challenges and milestones that differentiate stepfamilies from first-union families, such as loyalty issues involving children (Coleman et al., 2000; Papernow, 1984, 2015), conflicts between former spouses (Cartwright \& Gibson, 2013), the need to adjust to and create new family habits and routines (Papernow, 2015), and the introduction of an adjunct parental figure in the child(ren)'s life (Hetherington \& Stanley-Hagan, 2002). Furthermore, when stepfamilies try to replicate first-union families, feelings of frustration, anger, dissatisfaction, and self-deprecation frequently result (Emery, 2004; Ganong \& Coleman, 2016).

While some scholars (Bray, 1995; Bray \& Berger, 1993; Visher \& Visher, 1988) were early in identifying that specific interventions (i.e., the need to address loyalty conflicts or the continuing influence of the non-resident biological parent in the stepfamily life) were necessary to adapt treatment to the unique needs of stepfamilies, most researchers and clinicians have only recently expanded their recommendations to include interventions unique to this population. For example, Papernow (2015) advocates recognizing that one's status in a stepfamily is highly dependent on whether one is part of the inner circle of the family, or one is perceived as an outsider. Browning and Artelt (2012) underline the importance of examining the interpersonal mistaken assumptions that occur early in stepfamily formation and argue for a subsystem approach to therapy as necessary to reduce the chances that stepfamilies adopt dysfunctional patterns.

Even in the U.S., where publications and websites about stepfamilies are numerous, there are few outcome studies on stepfamily therapy (notable exceptions are Cartwright, 2003; Pasley et al., 1996; Visher \& Visher, 1988, 1996); of these, even fewer consider the therapists' perspective. The present paper adds to the scant literature on the topic by analyzing therapists' representations of stepfamilies. Such an investigation is particularly important if we consider that therapists' perspective and beliefs about their clients are reported to shape their clinical reasoning and the choices made during therapy (Higgs et al., 2008).

With regards to Italy, stepfamily research remains in its infancy; to our knowledge there is only one published study (Browning et al., 2010) addressing the representations held by a group of Italian therapists with regards to their stepfamily clients. The other few published works by Italian authors are either solely theoretical or based on few clinical cases (e.g., Bianca et al., 2005; Mazzoni, 2002). Moreover, despite the outlined differences, because little is known about the characteristics of Italian stepfamilies, Italian clinicians are likely to apply information from the American and international literature. For such reason a comparison between the Italian and American therapists' representations is worth considering, especially because this may help establishing how and to what extend the research outcomes and recommendations in the literature on the topic are actually implemented into clinical practice.

\section{Methods}

\section{Participants}

A total of 170 therapists agreed to participate in the study: 125 were Italian and 45 were American. The inclusion criterion was that they had had at least one stepfamily or stepfamily member as a client in therapy. In case of individual therapy, the presenting problem had to be explicitly related to the stepfamily in which the client resided. Therapists who took part in this study were recruited according to a purposive sampling method. When utilizing this sampling, socio-demographic and social characteristics are not to be automatically considered as relevant as they may overshadow the data collection (Breckenridge \& Jones, 2009).

The Italian sample. To obtain the Italian sample, Italian postgraduate training agencies $(N=251)$ offering continuing education to licensed psychotherapists were contacted via email and asked for the cooperation of trainees. Sixty-five agencies throughout Italy agreed to invite their trainees to participate, each providing one to three names for a total of 125 psychotherapists (34.4\% men and $65.6 \%$ women). All the participants had a Master's Degree in either psychology $(86.4 \%)$ or medicine $(13.6 \%)$ and were licensed to work as clinicians. About half of them worked in private practice $(51.2 \%)$, whereas $40.8 \%$ worked in both public and private arenas. Only $8 \%$ worked solely in the public arena. With regards to their theoretical orientation, the Italian therapists are divided as follows: $27.20 \%$ systemic, $17.59 \%$ integrated, $9.6 \%$ relational, $8.79 \%$ psychodynamic, $8.79 \%$ cognitive-behavioral, $\quad 7.20 \%$ gestaltic, $\quad 6.40 \%$ other, $5.60 \%$ analytic-transactional, $4.8 \%$ strategic, $4 \%$ humanistic.

Despite using convenience strategy, this sample appears to be representative of the overall therapists population in Italy, where the percentage of male clinicians is almost three times lower than that of females and most (around 75\%) therapists hold a Master's Degree in psychology (Baventore, 2014), whereas data regarding the place of work of Italian therapists are not available (however, in this study, both private practice and public services are uniformly represented).

With regards to training and continuing education on stepfamily issues, all but three Italian therapists reported having attended such education over the past three years. Moreover, $94.4 \%$ of them stated that they have discussed 
the topic with colleagues and other professionals, $83.2 \%$ said that they have read and studied books or articles about stepfamilies, $64.8 \%$ affirmed that they have attended conferences or seminars on the theme, 59.2\% worked with a supervisor and referred to him/her for clinical advice and guidance, and only $13.6 \%$ attended a special training course on stepfamilies.

The American sample. These 45 therapists came from 17 mental health agencies that were previously contacted either via email or in person by the second author of this study. At the time of the sample recruitment, all therapists were attending continuing education workshops in two large Eastern states, i.e., Pennsylvania and Florida. Of the sample, $28.9 \%$ were men and $71.1 \%$ were women. Of the American therapists, 12 were psychologists (26.7\%), nine were psychotherapists $(20.0 \%)$, two were psychiatrists $(4.4 \%)$, three were unlicensed psychotherapists $(6.7 \%)$, six were licensed clinical social workers (LCSW, 13.3\%), two were general social workers (MSW, 4.4\%), and 11 reported being other $(24.5 \%)$. The other category included those with a Master's Degree in counseling who completed the requirements for licensure. Most American clinicians worked in private practice (38.6\%), another $31.8 \%$ worked in public service agencies, and the remaining $29.6 \%$ worked in both the private and public sector (thus creating three homogeneous subgroups). With regards to their orientation, all but one therapist reported using an integrated model in their clinical practice.

Also the data collected from the American sample are representative of the overall therapists population in the U.S., where figures report a ratio equal to 2.1 active female therapists for every male in 2013 (APA, 2015).

Regarding their training and continuing education specific to working with stepfamilies, 55.6\% of American therapists reported having attended conferences or seminars on the theme, $44.4 \%$ read and studied books and articles on the topic, $40 \%$ worked with a supervisor, $13.3 \%$ discussed the topic with other colleagues, $11.1 \%$ attended special training courses, and almost all (93.3\%) took part in updating their clinical activity over the past three years.

The American sample is much more heterogeneous if compared to the Italian sample. Such a difference is due to the different educational pathways available in the two countries: While people who are willing to become therapists in the U.S. have a wide array of educational options, Italians can only become therapists after having completed a Master's Degree program in either psychology or medicine, followed by a one-year clinical training and a four-year specialty in psychotherapy during which they are usually taught one theoretical approach that will later likely become their preferred orientation. Social workers and other professionals working in the field of mental health (e.g., counselors) are not allowed to do therapy in Italy. While the Italian sample is more homogeneous in terms of therapist's educational background, clinicians vary greatly with regards to their theoretical orientation.
As such, these differences in the educational pathways and theoretical approach render the comparison between Italian and American clinicians even more meaningful.

Further, participants in both the Italian and American sample were recruited while attending continuing education courses, and most of them-irrespectively of nationality-stated that they received some sort of education about stepfamily issues in the past three years. Despite being highly educated about stepfamily dynamics, only $33.6 \%$ of the Italian therapists and $53.3 \%$ of the American therapists reported holding to a specific clinical model of intervention with these clients.

Theoretical saturation (Charmaz, 2015) was used to determine the final size of the two subsamples. Among the American participants, this saturation-i.e., the point at which the collection of further data does not add any new information and no new codes are generated while existing ones are both sufficiently dense and accurate and therefore sampling can cease (Charmaz, 2015)-was reached relatively quickly. Of the 67 categories identified to code their responses, 44 emerged from the first 15 interviews (see below, Instrument), suggesting that, despite the within group differences, these American therapists were similar in their responses, and this justifies the smaller sample size. Such was not the case with the Italian participants: Of the 120 categories identified to code their responses, 97 emerged once the 84th interview was collected. While progressively adding 41 extra interviews, the total set of categories (i.e., 120) was finally reached.

\section{Instrument}

To explore the clinicians' representations of stepfamilies, a semi-structured questionnaire comprised of openand close-ended questions was constructed. The questionnaire had both Italian and English versions and was developed by the first three authors. Translation and back-translation (Brislin, 1970) was used to guarantee conformity in the two versions. Next, a pilot study of 20 Italian and 20 American therapists, different than those sampled in the present study, was pursued to assess question clarity. The resulting reports and feedback did not alter the overall structure of the questionnaire, but changes in wording were useful in reducing ambiguity.

The questionnaire had two parts. The first part included questions about the therapists, their education, training and continuing education about stepfamilies, and their years of experience, both in general and in treating stepfamilies specifically. The second part included questions about the therapists' representation of stepfamilies and their clinical methods of work with them, using five open-ended questions: (1) Please list the first five words that come to your mind when you think of your work with stepfamilies. (2) Which are the most interesting aspects of working with stepfamilies? (3) What personal and professional characteristics can you count on for your work with stepfamilies? (4) What are, in your opinion, the step- 
family characteristics that facilitate the clinical work? (5) What are, in your opinion, the stepfamily characteristics that hinder the clinical work?

\section{Data analysis strategy}

The present study used a mixed methods approach (Johnson \& Onwuegbuzie, 2004) in which quantitative as well as quanti-qualitative data analytic strategies were used in sequence to analyze the composition of the two samples in terms of participants' education-training, continuing training, and clinical experience and the answers to the five open-ended questions respectively. While allowing researchers to gain an overall understanding of complex processes and phenomena in their idiosyncrasies (which is typical of qualitative studies), mixed methods approaches also permit to draw conclusions based on the relationships between variables (which is typical of quantitative studies) (Bentahar \& Cameron, 2015), and both of these features are consistent with our two research goals. Moreover, the use of a mixed methods design is justified by a pragmatic approach (Morgan, 2007), which conceives methodology as the convergence point between the abstract level of epistemology and the functional level of different research methods.

In order to gain on overview of the sample composition, descriptive statistics were calculated, and the two samples were compared using independent samples $t$-test and chi-square test in order to determine whether the therapists in our subsamples differ with regards to those variables relevant to this study (i.e., years of experience both in general and with stepfamilies, theoretical model, specific training to treat stepfamilies), especially given the heterogeneity outlined above. Effect sizes were also computed on these data using either Hedges's $g$ or correlation coefficients and interpreted according to Rosnow and Rosenthal (1996). Lastly, a multiplicity correction was performed to control the false discovery rate using the Holm-Bonferroni method. Content analyses (Mayring, 2000) were then performed on the therapists' answers to the five open-ended questions. These analyses were performed by two independent judges-both trained psychologists who were blind to the research questions and objectives-with the goal of reducing data variability by identifying latent factors and creating a smaller number of categories. Inter-rater agreement was computed to check for the level of agreement between judges in assigning a given answer to a given category (Hayes \& Krippendorff, 2007).

The categories resulting from the content analysis were then inserted in a software for textual analysis, i.e, T-LAB 4.1.1 PRO (Lancia, 2004; Margola, Donato, Accordini, Emery, \& Snyder, 2017; Margola, Facchin, Molgora, \& Revenson, 2010).

In this study, the T-LAB software was used to examine the characteristics of stepfamilies and stepfamily treatment emerging from the words of participants. Although the description of the full process underlying the software functioning is beyond the scope of this article, it should be remembered that T-LAB uses two types of computational units, i.e., lexical and context units. Lexical units (LU) are single words that together make up the corpus under analysis. In this study, lexical units correspond to the categories created to code the answers given by therapists in both samples. Context units (CU) correspond to the two subsets: The set of interviews of the Italian therapists made up of those categories used to code their answers (i.e., 120 categories), and the set of interviews of the American therapists made up of those categories used to code their answers (i.e., 67 categories).

The difference between LU and CU is key to understanding how T-LAB functions. The software computes co-occurrences (square matrix) or occurrences (rectangular matrix) patterns, analyzing the relationships between $\mathrm{LU}$ and $\mathrm{CU}$. While co-occurrence matrices refer to the number of times or frequency two or more LU are simultaneously present in the same portion of text, occurrence matrices refer to the number of times or frequency a given $\mathrm{LU}$ is present (occurs) within the entire corpus or one of its portions (CU). In particular, two different types of analyses were run, i.e., elementary context analysis and specificity analysis.

\section{Elementary context analysis}

This analysis is based on the co-occurrences logic and aims to identify the main concepts and themes that serve to organize the entire corpus and its CU. More specifically, the elementary context analysis provides a representation of the corpus main contents by generating a few thematic clusters. Clusters are obtained by transforming the text in a presence/absence matrix in which rows are constituted by $\mathrm{CU}$ (the two subsamples: Italian therapists and American therapists), and columns are constituted by code categories within the text. Variables and categories contained in the same cluster occur with the highest probability in the same text portion. Clustering is determined according to the maximum similarity with the cluster center so that all the elements within each cluster are maximally similar among themselves (within), while bearing the highest dissimilarity with elements in the other clusters (between). This first analysis provides two kinds of outputs: (a) smaller text portions or clusters, each constituted by a homogenous set of keywords and variables with their respective chi square values (generally, T-LAB applies this test to $2 \times 2$ tables; then the threshold value is $3.84[\mathrm{df}=1 ; \mathrm{P}<.05]$ or 6.64 $[\mathrm{df}=1 ; \mathrm{P}<.01]$ ); (b) a graphic factorial representation showing the position of the variables and clusters with respect to one another. This analysis allowed us to identify the main themes or categories organizing the text as well as to check whether Italian and American therapists fell into different clusters, indicating that they had different perceptions of stepfamilies. 


\section{Specificity analysis}

This analysis draws on the logic of occurrences and enables the researcher to check which LU (categories in our case) are typical (i.e., over-used) in a corpus subset (CU), comparing it with another subset. Typical LUs that are over-used in a given portion of text are calculated using chi-square test. In this case, we compared the categories used by the therapists in the Italian subset to those used by the therapists in the American subset in order to determine the differences in the two subsamples. This process allowed us to verify whether Italian and American clinicians used different categories in conceptualizing stepfamilies. The output of this analysis is a table reporting the following data: (a) a list of the over- and underused categories within each corpus subset; (b) their chi square values; (c) the number of times each category was used within each subset; and (d) the number of times each category was used in the whole text.

\section{Results}

\section{Sample characteristics of the Italian and American therapists}

After having been corrected for multiple testing using the Holm-Bonferroni method, first-level results did not show any significant differences between the Italian and American therapists in terms of (a) the overall number of clinical cases treated (Americans: $\mathrm{M}=79.53, \mathrm{SD}=80.72$; Italians: $\mathrm{M}=42.86, \mathrm{SD}=36.00 ; \mathrm{t}[50.44]=-2.94, \mathrm{P}=.10$, $\mathrm{g}=.71$ ); (b) the number of stepfamily cases treated over the course of their practice (Americans: $\mathrm{M}=96.62$, $\mathrm{SD}=171.77$; Italians: $\mathrm{M}=26.10, \mathrm{SD}=32.64$; $\mathrm{t}[45.15]=-$ $2.74, \mathrm{P}=.12, \mathrm{~g}=.76$ ); (c) the number of years of practice in general (Americans: $\mathrm{M}=14.49, \mathrm{SD}=9.85$; Italians: $\mathrm{M}=17.06, \mathrm{SD}=9.94 ; \mathrm{t}[78.43]=1.49, \mathrm{P}=.25, \mathrm{~g}=.25)$; (d) the years of practice with stepfamilies (Americans: $\mathrm{M}=12.31$, $\mathrm{SD}=8.40$; Italians: $\mathrm{M}=10.07, \mathrm{SD}=36.00 ; \mathrm{t}[154.39]=0.41$, $\mathrm{P}=.58, \mathrm{~g}=.07)$. Results of the independent samples t-tests proved to be significant only with regards to the number of stepfamily cases seen in the past year; more specifically, American therapists were found to have seen more stepfamily cases in the past year $(\mathrm{M}=13.6, \mathrm{SD}=22.73)$ when compared to their Italian counterparts $(\mathrm{M}=5.3$, $\mathrm{SD}=7.34), \mathrm{t}(47.35)=-2.41, \mathrm{P}=.008, \mathrm{~g}=.63$. Moreover, while more than half $(53.3 \%)$ of the American clinicians stated to have a specific model for treating stepfamilies, the same is true for only $33.6 \%$ of the Italian clinicians and such difference is statistically significant $\left(\chi^{2}=5.45\right.$, $\mathrm{P}=.03, \mathrm{r}=.18$ ).

\section{Content analysis}

As anticipated, a total of 120 categories were created to code the answers from Italian therapists, whereas 67 categories were created for the answers given from Amer- ican therapists. Categories created for the classification of Italian data only partially overlapped $(\mathrm{N}=49)$ with those that emerged from the American data. Thus, 18 extra categories were purposively created for the American responses. Altogether, irrespectively of nationality, the categories were 138 (49 of which, as explained, being in common between Italian and American therapists).

\section{Interrater agreement}

There was a good level of agreement between coders for all the variables in the Italian responses to the openended questions, as all alpha values were higher than the acceptability threshold, conventionally fixed at .667 (Hayes \& Krippendorff, 2007). Alphas ranged from .71 (question 4) to .85 (question 5). For the American sample, question 4 resulted in an interrater reliability (alpha) coefficient slightly lower than the desired $.667(\alpha=.61)$, but adequately close to the level of acceptability to be considered valid. The values for all other answers were above the acceptability limit, ranging from .70 (question 2) to .84 (question 3). Collectively, these results confirm the validity and internal coherence of the categories found.

\section{Elementary context analysis}

As noted earlier, the elementary context analysis generates clusters composed of words and variables that refer to a homogeneous theme. Here, this analysis aimed at checking whether the responses of Italian and American therapists fell into different clusters, as this would imply that therapists in the two groups use different keywords and statements to describe stepfamilies and their job as therapists. The categories emerged through the content analysis were inserted in T-LAB (Lancia, 2004), together with certain variables: Nationality (with two modalities, i.e., 1=Italian; 2=American); years of experience (with six modalities, i.e., SFEXP_1: $\leq 1$ year experience in treating stepfamilies; SFEXP_2: 1-5 year experience; SFEXP_3: 6-10 year experience; SFEXP_4: 11-15 year experience; SFEXP_5: 16-20 year experience; SFEXP_6: $\geq 21$ year experience); specific training for treating stepfamilies (with two modalities, i.e., Model 0: No training on stepfamilies; Model 1: Trained for treating stepfamilies); and the open-ended question number (with 5 modalities, i.e., QTION_1=question 1; QTION_2=question 2; QTION_3=question 3; QTION_4=question 4; QTION_5=question 5; see Method, Instrument).

Even if these four variables were inserted in the analysis, we will mainly discuss results regarding the variable nationality and-to a lesser extent-open-ended question number since the other covariates do not play a significant role in the cluster formation, as clearly shown in Figure 1, where they all appear to be concentrated in the center of the factorial space, thus evidencing their non-discriminant power.

T-LAB first generated a four-cluster solution, one of 
which only accounted for $1.72 \%$ of the variance. For this reason, a more parsimonious three-cluster solution was created. Figure 1 shows the graphical distribution of the clusters and variables in the factorial space.

\section{Cluster one (31.47\% of the total variance): Families in therapy}

The categories contained in Cluster one do not refer to stepfamilies, but more generally to those characteristics that may facilitate or hinder treatment with both firstunion families and stepfamilies (Figure 1). The variables that mostly feature this cluster-with moderate-to-large effect sizes-are question four (QTION_4, $\chi^{2}(1)=19.75$, $\mathrm{P}<.01, \mathrm{r}=.34)$ and five $\left(\mathrm{QTION}\right.$ 5, $\chi^{2}(1)=5.08, \mathrm{P}<.01$, $\mathrm{r}=.17)$ which gave therapists the chance to discuss the characteristics that, respectively, may facilitate or hinder the therapeutic process in a broader sense. The lemmas in this cluster are not characteristic of a specific subsample, they rather refer to the representations about therapy that are shared by both Italian and American therapists. In particular, (a) the underestimation of the complexity of treatment $\left(\chi^{2}(1)=23.65, \mathrm{P}<.01, \mathrm{r}=.39\right)$; (b) the pressure exerted on the family by past traumas $\left(\chi^{2}(1)=8.87, \mathrm{P}<.01, \mathrm{r}=.27\right)$; and (c) the lack of commitment and hope towards therapy $\left(\chi^{2}(1)=8.87, \mathrm{P}<.01, \mathrm{r}=.24\right)$, all appear in this cluster as hinders to the success of therapy. On the contrary, (a) having a supportive extended family $\left(\chi^{2}(1)=22.72, \mathrm{P}<.01\right.$, $\mathrm{r}=.43$ ); (b) the capacity, regardless of conflict, for couples to be dedicated to parenting and attentive to children's needs $\left(\chi^{2}(1)=22.03, \mathrm{P}<.01, \mathrm{r}=.39\right)$; (c) the couple's willingness to stay united and share life goals $\left(\chi^{2}(1)=20.39\right.$, $\mathrm{P}<.01, \mathrm{r}=.35)$; (d) the ability of members to fulfill clear roles in the family $\left(\chi^{2}(1)=15.31, \mathrm{P}<.01, \mathrm{r}=.32\right)$; and (e) the ability to be open and flexible to change for families or stepfamilies as a whole $\left(\chi^{2}(1)=4.3, \mathrm{P}<.01, \mathrm{r}=.16\right)$, all appear as elements favoring the success of therapy. Correlation values (r) suggest a moderate to high practical significance.

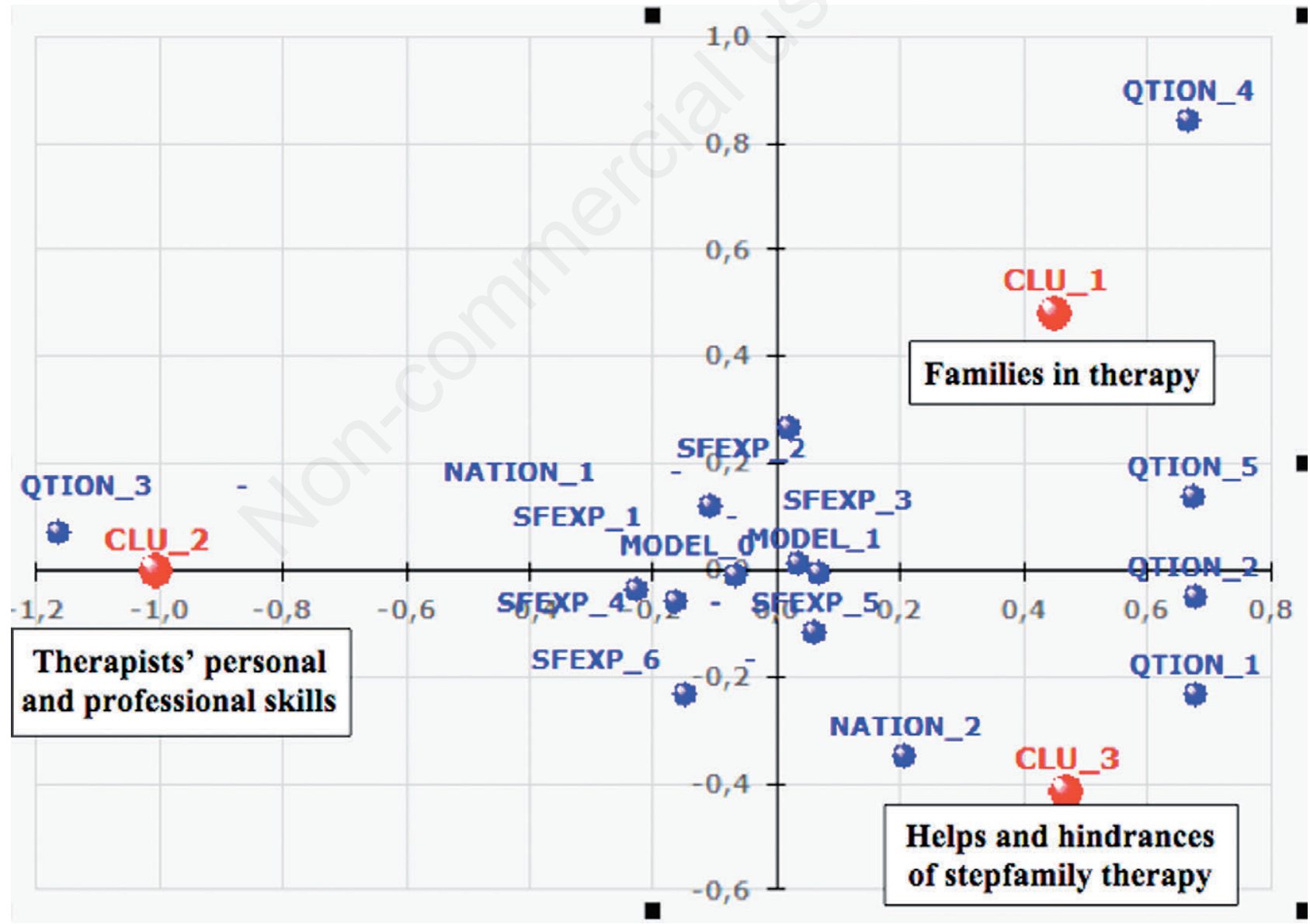

Figure 1. Elementary context analysis: Distribution of clusters and variables. Nation_1=Italy; Nation_2=U.S.; QTION_1=question one; QTION_2=question two; QTION_3=question three; QTION_4=question four; QTION_5=-̄uestion five; Model 0=no training on stepfamilies; Model 1=trained for treating stepfamilies; SFEXP_1=less than one year treating stepfamilies; SFEXP_2=1-5 years treating stepfamilies; SFEXP_3=6-10 years treating stepfamilies; SFEXP_4=11-15 years treating stepfamilies; SFEXP_5=16-20 years treating stepfamilies; SFEXP_6= $\geq 21$ years treating stepfamilies. 
Cluster two (32.75\% of the total variance): Therapists'personal and professional skills

While Cluster one is focused on the family and its characteristics, the categories in Cluster two refer to the therapist, his/her personal and professional characteristics and skills, and his/her actions during therapy. To support this, examining Figure 1, we can see that the variable question three (QTION 3, $\chi^{2}(1)=181.6, \quad \mathrm{P}<.01$, $\mathrm{r}=1.03$ )-that asked therapists to list the personal and professional characteristics that helped them in their practice with stepfamilies-strongly characterizes this cluster while also showing a high practical significance. Specifically, therapists listed: (a) the presence of relational abilities and personal skills $\left(\chi^{2}(1)=39.73, \mathrm{P}<.01, \mathrm{r}=.48\right)$; and (b) having a positive attitude towards the clients $\left(\chi^{2}(1)=18.92, \mathrm{P}<.01\right.$, $\mathrm{r}=.33$ ). The professional characteristics facilitating the therapists' work with stepfamilies in particular (vs. families in general) involve: (a) adhering to a theoretical orientation $\left(\chi^{2}(1)=96.03, \mathrm{P}<.01, \mathrm{r}=.76\right.$ ); (b) being informed and keeping updated through attending seminars $\left(\chi^{2}\right.$ $(1)=40.05, \mathrm{P}<.01, \mathrm{r}=.48$ ); (c) being experienced in the treatment of stepfamilies $\left(\chi^{2}(1)=30.58, \mathrm{P}<.01, \mathrm{r}=.42\right)$; (d) having specific knowledge about stepfamily functioning $\left(\chi^{2}(1)=23.7, \mathrm{P}<.01, \mathrm{r}=.41\right)$; and (e) reading specialized literature $\left(\chi^{2}(1)=8.36, \mathrm{P}<.01, \mathrm{r}=.27\right)$. With reference to those elements of setting and actions during therapy, participants mentioned several factors that contributed to the success of therapy. These included: (a) receiving help from others through supervision $\left(\chi^{2}(1)=44.93, \mathrm{P}<.01, \mathrm{r}\right.$ $=.61)$; (b) working in teams or with a colleague $\left(\chi^{2}\right.$ $(1)=23.66, \mathrm{P}<.01, \mathrm{r}=.39)$; (c) using techniques $\left(\chi^{2}\right.$ $(1)=15.56, \mathrm{P}<.01, \mathrm{r}=.34)$ other than those specific for the treatment of stepfamilies; (d) establishing a positive therapeutic alliance $\left(\chi^{2}(1)=5.18, \mathrm{P}<.01, \mathrm{r}=.17\right)$; and (e) supporting and validating the various stepfamily members $\left(\chi^{2}\right.$ $(1)=5.18, P<.01, r=.24)$. As shown in Figure 1, the variable Nation_1 $\left(\chi^{2}(1)=9.15, \mathrm{P}<.01, \mathrm{r}=.23\right)$, referring to the Italian therapists, falls in this cluster. Even though the correlation value indicates a moderate effect size and thus caution is required, this result suggests that Italian participants described their work with stepfamilies using words that are related to their personal and professional skills together with the actions and techniques they use in therapy to a greater extent than their American counterparts.

\section{Cluster three (35.78\% of the total variance): Helps and hindrances of stepfamily therapy}

The final cluster focused on characteristics of stepfamily dynamics that are relevant to the clinical process. In Cluster three, American therapists (Nation_2, $\chi^{2}$ $(1)=19.29, \mathrm{P}<.01, \mathrm{r}=.33$ ) predominate (Figure 1). Thus, while Cluster two is most representative of the perceptions of Italian therapists, Cluster three is more strongly associated with the representations of American therapists, showing a moderate-to-large effect size. Beyond listing some generic factors that might positively or neg- atively influence the outcome of the therapeutic process (e.g., the need for personal internal resources, $\chi^{2}$ $(1)=40.88, \mathrm{P}<.01, \mathrm{r}=.49$; the communication between family members, $\chi^{2}(1)=10.65, \mathrm{P}<.01, \mathrm{r}=.25$; the presence of negative feelings, $\chi^{2}(1)=8.89, \mathrm{P}<.01, \mathrm{r}=.23$, or dysfunctional dynamics among family members, $\chi^{2}(1)=6.71$, $\mathrm{P}<.01, \mathrm{r}=.20$ ), this cluster mainly contains categories referring to those dynamics that are generally considered to be specific of stepfamilies: (a) loyalty conflicts which arise from power struggles $\left(\chi^{2}(1)=11.39, \mathrm{P}<.01, \mathrm{r}=.26\right)$; (b) the need to come to terms with the complexity inherent in all stepfamilies $\left(\chi^{2}(1)=9.97, \mathrm{P}<.01, \mathrm{r}=.24\right)$; (c) the presence of conflicts between former spouses $\left(\chi^{2}(1)=8.43\right.$, $\mathrm{P}<.01, \mathrm{r}=.22)$; (d) the need to promote the integration of all the stepfamily subsystems $\left(\chi^{2}(1)=7.31, \mathrm{P}<.01, \mathrm{r}=.21\right)$; and (e) the elaboration of grief related to the end of past relationships $\left(\chi^{2}(1)=6.06, \mathrm{P}<.01, \mathrm{r}=.19\right)$. In contrast with their Italian counterparts-who seem to be more focused inwards-American therapists, when thinking of stepfamilies, tend to move their attention outwards, that is, on the characteristics of the stepfamily itself. This is also evidenced by the fact that the variable question one (QTION_1, $\left.\chi^{2}(1)=52.5, \mathrm{P}<.01, \mathrm{r}=.56\right)$, that asked therapists to freely associate some words to describe stepfamilies per se, strongly characterizes this cluster with a high effect size.

\section{Specificity analysis}

T-LAB was also used to perform a specificity analysis on each of the corpus subsets (Italian vs. American therapists). The aim was to determine which categories are predominantly used by each of the two subgroups. This allowed us to explore the differences in the terms used by the therapists and thus the differences in their concept and representation of stepfamilies and stepfamily therapy. Let's recall that this analysis creates two list of categories, one showing the over-used specificities, or the categories that are predominantly used in a given subset, and the other showing the under-used specificities, or the categories that are least used in the same subset. These results appear in Tables 1 and 2 showing the categories that are over- and under-used by the Italian and American therapists, respectively. In addition to reporting chi-square values, the number of times each category is used in the subset (SUB) as well as the number of times the same category is used in the whole corpus (TOT) are reported.

Compared to their counterparts, Italian therapists used words related to a rather limited number of categories (five in all), whereas the responses of the American therapists appear to be broader (14 categories) and refer to different underlying concepts and ideas.

By comparing Tables 1 and 2 we can immediately acknowledge that, while the categories used by the Italian subgroup were generic and could easily be adapted to any client, those used by Americans referred to specific and distinctive features of stepfamilies. 
As shown in Table 2, American therapists seemed more aware of the specific problems and issues that stepfamily members may encounter and that this type of understanding may affect treatment. For example, they made reference to (a) the presence of different cultures, habits, and stories that need to be negotiated in a newly formed stepfamily; (b) the presence of conflictual relationships between former partners-a typical stepfamily characteristic that may bring members into therapy; along with (c) the presence of powerful and unrealistic expectations and fantasies about an easy transition and instant love between all members. Moreover, American therapist made reference to their awareness of stepfamily dynamics, having lived in one themselves, a category that was not mentioned by Italian therapist (see, again, Tables 1 and 2). Therapeutic actions that were commonly reported to be effective for treating stepfamilies, such as trying to integrate and create a common ground between subsystems along with the need for a specific and continuous training (i.e., seminars and training on stepfamily issues), were also mentioned by American therapists only.

In addition to being less specific about stepfamily dynamics, Italian therapists were more self-focused, prima- rily referring to their theoretical orientation and the importance for clinicians to maintain a positive attitude towards the clients, then listing the lack of commitment and hope towards therapy as the main problem hindering the process (Table 1). Two out of the three categories listed in Table 1 are therefore focused on therapist role rather than on family. Comparatively, only four categories of the 11 most used by U.S. participants pertain to the clinician, and they refer to: (a) the need to keep updated through receiving training or attending seminars on stepfamily issues; (b) the need to be supervised by a senior colleague; (c) the awareness of stepfamily dynamics due to having lived in one; and (d) the technique of integrating the various stepfamily subsystems. It is noteworthy that three of the four categories mentioned above (i.e., seminars and training on stepfamily issues, being the therapist a member of a stepfamily him/herself, and integration of the stepfamily subsystems) are clearly connected to stepfamilies, whereas this was not the case for any of the categories resulting from the specificity analysis with the Italian participants, who, again, referred to more general, all encompassing aspect of their work (see, again, Tables 1 and 2).

Table 1. Specificity analysis (Italian subsample).

\begin{tabular}{lccclccc}
\hline Over-used categories & $\chi^{2}$ & SUB & TOT & Under-used categories & SUB & TOT \\
\hline Importance of theoretical orientation & 25.71 & 80 & 81 & $\begin{array}{l}\text { Presence of different cultures, subcultures, } \\
\text { and stories }\end{array}$ & -51.37 & 6 & 31 \\
\hline Therapist's positive attitude towards clients & 13.52 & 101 & 113 & Integration of the stepfamily subsystems & -6.49 & 27 & 46 \\
\hline Lack of commitment and hope towards therapy & 8.12 & 51 & 56 & & & \\
\hline
\end{tabular}

SUB, times the category appears in the Italian subsample; TOT, times the category appears in the whole corpus. Chi square values are computed considering a threshold value of 3.84 (df $=1$; $\mathrm{P}<0.05$ ).

Table 2. Specificity analysis (American subsample).

\begin{tabular}{lccccccc}
\hline Over-used categories & $\chi^{2}$ & SUB & TOT & Under-used categories & SUB & TOT \\
\hline Presence of different cultures, subcultures, and stories* & 50.07 & 25 & 31 & Importance of theoretical orientation & -25.54 & 1 & 81 \\
\hline Positive exchanges between stepfamily members & 30.57 & 12 & 13 & Therapist's positive attitude towards clients & -13.36 & 12 & 113 \\
\hline Support from extended family & 23.40 & 15 & 21 & Lack of commitment and hope towards therapy & -8.04 & 5 & 56 \\
\hline Seminars and training on stepfamily issues* & 14.85 & 20 & 38 & & \\
\hline Conflict between former partners* & 7.97 & 19 & 43 & & \\
\hline Dedication to parenting and attention towards children & 7.96 & 9 & 16 & & \\
\hline Lack or dysfunctional communication & 7.75 & 5 & 7 & & \\
\hline Therapist receiving supervision & 6.16 & 16 & 37 & & \\
\hline Integration of the stepfamily subsystems* & 6.09 & 19 & 46 & & \\
\hline Therapist as a member of a stepfamily him/herself* & 5.10 & 12 & 27 & & \\
\hline Presence of idealization and unrealistic expectations* & 5.04 & 8 & 16 & & \\
\hline
\end{tabular}

SUB, times the category appears in the American subsample; TOT, times the category appears in the whole corpus. Chi square values are computed considering a threshold value of 3.84 ( $\mathrm{df}=1$; $\mathrm{P}<0.05)$. * Specific to the treatment of stepfamilies. 


\section{Discussion}

In the current study, we discussed the representations that a group of American and Italian clinicians hold about stepfamilies as well as the challenges faced when working with these families, including the resources used to optimize treatment and the obstacles hindering the therapeutic process. This exploratory study offers some preliminary considerations with regards to two separate realms: The cross-national comparison and therapy with stepfamilies.

Although no difference was found between the two samples in terms of clinical experience, results show that, compared to Italian therapists, American therapists have seen a greater number of stepfamily cases in the past year. While such difference may be partly due to the time-limited nature of therapy in the U.S., as it is often paid by insurance companies, American therapists are also more likely to have seen stepfamily members due to their greater prevalence among the U.S. population (U.S. Census Bureau, 2012). Not only are Italian stepfamilies less common and therefore rarer to be seen as clients in therapy, they might also often not be recognized (Vetere, 2017 ) both because of the stigmatization that leads their members not to mention they are part of a stepfamily as well as due to the well known bias according to which we (common people and therapists alike) are drawn to discard specificities in order to form general ideas while trying to accommodate new information into already existing schemas (Lord, Ross, \& Lepper, 1979) and therefore tend to consider stepfamilies as more similar than different from other family forms.

Another important difference between the groups is that more than half $(53.3 \%)$ of the Americans stated that they used a specific intervention model in their work with stepfamilies compared to only about one third (33.6\%) of the Italians. It may be that these differences are the result of the unique educational paths and professional training that clinicians receive in the two countries. While after having been trained in a single theoretical model (e.g., psychodynamic, cognitive-behavioral, relational, systemic) for four years after graduation in order to become psychotherapists, Italian clinicians tend to give greater emphasis to their orientation, Americans are licensed to practice psychotherapy throughout multiple pathways and are exposed to different theoretical orientations. Within such a broad and variegated context, American therapists in our sample might have felt the need to narrow down their competencies to gear them to the specific needs of stepfamily members. Moreover, on a more general level, not only do American clinicians start practicing earlier in their education (often as part of a Master's degree program) and have more opportunity to learn in their internships, they are also more frequently exposed to specific models based on research outcomes rather than a theorybased approach. Thus, the two countries hold different professional training cultures; the American training cul- ture is more context-specific and problem focused whereas the Italian training culture is theory driven. From a wider perspective, this dissimilarity between Italian and American therapists might also reflect a difference between the two cultures in general. Americans are more practical and oriented toward action, whereas Italians, and Europeans in general, are more focused on reflection and epistemology (Flamm, Lachs, \& Skowroñski, 2008). While such explanation for the observed differences between the two groups appears to be logical and culturallyinformed, it has to be retained as a hypothesis as alternative interpretations of results are possible and further research is needed. For example, the lack of specificity in the Italian therapists' representations of stepfamilies might be due to the paucity of research addressing the topic. Among the available research, theoretical studies are usually not appealing to practitioners due to the lack of immediate implications for clinical practice and the massive use of research jargon (Bondi \& Fewell, 2016). On the other end, studies reporting clinical cases often lack the necessary information to be generalized. This issue brings back the longstanding matter about the existence of a gap between research and clinical practice.

The outlined differences in the education and training received by these two groups of therapists likely affect the way they work with and perceive stepfamilies. In this respect, results showed a difference with reference to the capability of recognizing and being aware of the specific stepfamily dynamics. In particular, American therapists listed many specific stepfamily characteristics, whereas Italian therapists described stepfamilies in more generic terms, often overlapping them with first-union families. In their understanding of stepfamilies dynamics, Italians focused on categories that, in many cases, might be suitable for all families (see Cluster 2 and Table 1), whereas Americans reported more distinctive features of stepfamilies (see Cluster 3 and Table 2).

Clearly, our results suggest that the American clinicians who took part in this research were more accustomed to stepfamilies and more keen to recognize their clients' problems as connected to being in a stepfamily. In particular, American therapists were more likely to highlight issues of loyalty, complexity, and the expected tensions with former spouses-all features considered as unique to stepfamilies by the international literature on the topic (e.g., Cartwright \& Gibson, 2013; Ganong et al., 2002; Hetherington \& Stanley-Hagan, 2002; Stewart, 2005). Conversely, Italian therapists were less likely to comment on specific characteristics and issues brought up in stepfamilies being, on the contrary, more focused on themselves. More specifically, Italian therapists assign more importance to their role as therapists, focusing on their need for theory and general techniques as well as on their own attitude towards their clients. Even if they focus on themselves as clinicians, Italians did not report using specific techniques to treat stepfamilies. In part, this lack of specificity may also be due to 
the greater stigma still attached to divorce and remarriage in the Italian culture (Bogliolo \& Bacherini, 2010; Hantrais $\&$ Letabiler, 2014), as well as to the, above mentioned, infrequent occurrence of remarriages and formal co-habitations in Italy (ISTAT, 2015).

Along with nationality, the variable question number has the most significant role in the clusters formation, while other covariates (e.g., years of experience, theoretical orientation, specific model) do not appear as influence factors shaping the clusters. While these results reinforce our hypothesis that Italian and American therapists are indeed different in terms of their representations of stepfamilies, it has to be acknowledged that what mostly shapes the clinicians' answers are the questions themselves, thus indicating both the clarity of the questions as well as the compliance of both the Italian and American clinicians to the task.

Besides the above mentioned differences, both the American and Italian participants seem to agree on some factors that may help or hinder the therapeutic process. These factors are not specific to the treatment of stepfamilies, but they are key in determining the success or failure in any treatment. For example, the lack of commitment towards therapy along with the underestimation of the potential effort required are known to significantly affect the therapeutic process (e.g., Bachelor, Laverdiere, Gamache, $\&$ Bordeleau, 2007). Parental competence and social support by extended family and friends also appeared among the categories conceived as most important by therapists in our subsamples and are found to be positive characteristics helping families overcome critical moments (Couchenour \& Chrisman, 2016; Hogan, Linden, \& Najarian, 2002).

\section{Implications for practice and limitations}

American and Italian therapists appeared to focus on different characteristics and made reference, at least partially, to different categories and representational domains when thinking of stepfamilies. The focus on oneself as a therapist and one's theoretical orientation model may overshadow the importance of having a specific model for the treatment of stepfamilies. Given the emphasis on theory during their training as psychotherapists and the simultaneous lack of national studies addressing stepfamily issues, it is not surprising that, when faced with the complexity and volatility of such families, Italian clinicians tended to hold on to that model. However, while having a solid theoretical ground is undoubtedly crucial, Italian therapists may run the risk of loosing sight of the stepfamily peculiar issues and be self-reinforced in the idea of the adequateness of a one size fits all treatment. In their overlapping stepfamilies and first-union family functioning, the Italian therapists in our sample seem to fall victim of the same pitfalls stepfamily members usually face. The adoption of a nuclear family ideology (Ganong \& Coleman, 2016) on the therapists' side may have profound ef- fects on their practice as it may lead them to stigmatize or further marginalize stepfamily members.

We suggest that Italian therapists may benefit from psychoeducational programs in order to be able to cascade their knowledge to stepfamily members; as a matter of fact, psychoeducation is reported to aid normalization and decrease the feelings of isolation often reported by stepfamily members (Papernow, 2015). Moreover, programs designed for Italian clinicians should promote a more extensive awareness of the unique stepfamily dynamics and the suitable techniques to treat their issues, as both are known to promote therapeutic success and satisfaction from the perspectives of both therapist and family members (e.g., Browning \& Artelt, 2012; Gurman, 2008).

Contrarily to their Italian counterparts, American therapists not only endorsed the peculiarities and complexities of stepfamilies more frequently, they also seemed to hold a more realistic view of these family systems, being able to detect their resources and, most of all, the struggles they face. However, this focus on the client may result in taking a less reflective stance and in a lack of awareness on how one's personal and professional style may affect therapy. While an attention towards the specific characteristics of stepfamily intervention has been documented to reduce dropout and increase commitment (Gurman, 2008; Pasley, Koch \& Ihinger-Tallman, 1994), there may also be a downside to over-specialization. If one is too focused on the unique aspects of a family, he or she might lose sight of the features they have in common with other family forms and with families in general, thus leading to further marginalization as well as to a lack of awareness of the common factors at the basis of any therapeutic job (Sprenkle \& Blow, 2004). In line with these findings, we suggest that programs in the United States should focus more on enhancing the therapists' ability to reflect over their own practice and the actions undertaken during therapy as well as underline the similarities between stepfamilies and other family forms. Therapists' awareness of the non-specific factors influencing the therapeutic process may actually lead to more positive outcomes and to greater client satisfaction and compliance with treatment (Beutler et al., 1994; Elliott et al., 2011). Therapists' training and continuing education programs should seek to assess and keep into greater account the therapists' representations and perceptions as these kind of programs have been found to have a much greater impact on actual practice (Casper, 2007).

\section{Conclusions}

Even though we believe this study gives a unique insight on the therapists' perception of stepfamilies, we have to acknowledge the presence of several limitations. First, despite our attempt to discuss our results also in terms of the cultural differences between the two countries considered, cultural, political, religious, and ethnic variables 
might have an influence in explaining the differences in the wording and narratives used by the therapists in our sample. Therefore, any comparisons between the two groups should be considered as exploratory in nature and outcomes as suggestive at best. Moreover, the relatively small size of the two subgroups as well as the heterogeneity of the American subsample in terms of education, professional degrees, licensing, and training, together with its limited geographical and ethnical representativeness, limits the possible comparisons between the two countries as well as the potential generalizability of our findings. As already done in other similar studies (e.g., Percy et al., 2014), we did not attempt to control for such differences because we believe they strongly mirror the characteristics and educational pathways of the therapists in each of the two countries under analysis and therefore offer a rather representative picture. Even though such limitations suggest the need for a cautious approach to results interpretation and generalization, we believe that this first-ofa-kind exploratory study might provide useful information for future research.

\section{References}

Altmaier, E.M., \& Hansen, J.C. (Eds.). (2011). The Oxford handbook of counseling psychology. Oxford, UK: Oxford University Press.

Bachelor, A., Laverdiere, O., Gamache, D., \& Bordeleau, V. (2007). Client's collaboration in therapy: Self-perceptions and relationships with client psychological functioning, interpersonal relations, and motivation. Psychotherapy: Theory, Research, Practice, Training, 44(2), 175-192. doi: 10.1037/0033-3204.44.2.175

Baventore, D. (2014). Psicologi in Italia: fotografia della categoria e confronto con l'estero [Psychologists in Italy: A snapshot of the profession and comparisons with other foreign countries]. Retrieved from: http://www.psicologiasistemica.net/wp/2014/04/10/1141/\#axzz4eTwDwbuy

Bentahar, O., \& Cameron, R. (2015). Design and implementation of a mixed method research study in project management. The Electronic Journal of Business Research Methods, 13(1), 3-15.

Beutler, L.E., Machado, P.P.P., \& Neufeldt, S. (1994). Therapist variables. In A.E. Bergin \& S.L. Garfield (Eds.), Handbook of psychotherapy and behavior change (4th ed., pp. 259269). New York, NY: Wiley.

Bianca, C.M., Malagoli Togliatti, M., \& Micci, A.L. (2005). Interventi di sostegno alla genitorialità nelle famiglie ricomposte. Giuristi e psicologi a confronto [Supportive interventions for parents in stepfamilies. Legal experts' and psychologists' views compared]. Milan, Italy: FrancoAngeli.

Bogliolo, C., \& Bacherini, A.M. (2010). Manuale di mediazione familiare. Proteggere i figli nella separazione [Manual of family mediation. How to protect children during separation]. Milan, Italy: FrancoAngeli.

Bondi, L., \& Fewell, J. (2016). Practitioner research in counseling and psychotherapy. The power of examples. London, UK: Palgrave Macmillan.

Bray, J.H. (1995). Family oriented treatment with stepfamilies.
In R. Mikesell, D.D. Lusterman, \& S. McDaniel (Eds.), Integrating family therapy: Handbook of family psychology and systems theory (pp. 125-140). Washington, DC: APA Books. doi: 10.1037/10172-007

Bray, J.H., \& Berger, S.H. (1993). Developmental issues in stepfamily research project: Family relationships and parentchild interactions. Journal of Family Psychology, 7(1), 7-17. doi: 10.1037/0893-3200.7.1.76

Breckenridge, J., \& Jones, D. (2009). Demystifying theoretical sampling in grounded theory research. Grounded Theory Review, 8(2), 113-126.

Brislin, R.W. (1970). Back-translation for cross-cultural research. Journal of Cross-Cultural Psychology, 1(3), 185216. doi: $10.1177 / 135910457000100301$

Browning, S., Accordini, M., Gennari, M., \& Cigoli, V. (2010). How therapists view stepfamilies: An analysis of Italians clinicians' representations. In V. Cigoli \& M. Gennari (Eds.), Close relationships and community psychology: An international perspective (pp. 15-33). Milan, Italy: FrancoAngeli.

Browning, S., \& Artelt, E. (2012). Stepfamily therapy: A 10-step clinical approach. Washington, DC: APA Books. doi: 10.1037/13089-000

Browning, S., \& Bray, J.H. (2009). Treating stepfamilies: A subsystem-based approach. In M. Stanton \& J. Bray (Eds.), The Wiley-Blackwell handbook of family psychology (pp. 487498). Oxford, UK: Wiley-Blackwell. doi: 10.1002/ 9781444310238.ch33

Cartwright, C. (2003). Therapists' perceptions of bioparent-child relationships in stepfamilies: What hurts? What helps? Journal of Divorce \& Remarriage, 38(3-4), 147-166. doi: $10.1300 / \mathrm{j} 087 \mathrm{v} 38 \mathrm{n} 03 \_08$

Cartwright, C., \& Gibson, K. (2013). The effects of co-parenting relationships with ex-spouses on couples in stepfamilies. Family Matters, 91, 18-28.

Casper, E.S. (2007). The theory of planned behavior applied to continuing education for mental health professionals. Psychiatric Services (Washington, D.C.), 58(10), 1324-1329. doi:10.1176/appi.ps.58.10.1324

Charmaz, K. (2015). Constructing grounded theory (2nd ed.). London, UK: Sage.

Coleman, M., \& Ganong, L.H. (1990). Remarriage and stepfamily research in the 1980s: Increased interest in an old family form. Journal of Marriage and the Family, 52, 925-940. doi: $10.2307 / 353311$

Coleman, M., Ganong, L.H., \& Fine, M. (2000). Reinvestigating remarriage: Another decade of progress. Journal of Marriage and the Family, 62, 1288-1307. doi: 10.1111/j.17413737. 2000.01288.x

Couchenour, D., \& Chrisman, J.K. (2016). The SAGE encyclopedia of contemporary early childhood education. London, UK: Sage. doi: 10.4135/9781483340333

Dattilio, F., Piercy, F., \& Davis, S. (2014). The divide between "evidence-based" approaches and practitioners of traditional theories of family therapy. Journal of Marital and Family Therapy, 40, 5-16. doi: 10.1111/jmft.12032

DeAngelis, T. (2015). In search of cultural competence. Monitor on Psychology, 46(3), 64. doi: 10.1037/e520422015-022

Elliott, R., Watson, J.C., Bohart, A., \& Greenberg, L.S. (2011). Empathy. Psychotherapy, 48(1), 43-49. doi: 10.1037/ a0022187

Emery, R.E. (2004). The truth about children and divorce. Dealing with the emotions so you and your children can thrive. New York, NY: Viking. 
Flamm, M.C., Lachs, J., \& Skowroñski, K.P. (2008). American and European values: Contemporary philosophical perspectives. Newcastle, UK: Cambridge Scholars Publishing.

Fisher, B.L., \& Sprenkle, D.H. (1978). Therapists' perceptions of healthy family functioning. International Journal of Family Counseling, 6(2), 9-18. doi: 10.1080/01926187808250283

Ford, S.C., \& Hecker, L.L. (2008). The therapist's notebook: More homework, handouts, and activities for use in psychotherapy (vol. 3). New York, NY: Routledge. doi: 10.4324/9780203888797

Fürnkranz-Prskawetz, A., Vikat, A., Philpov, D., \& Engelhardt, H. (2003). Pathways to stepfamily formation in Europe: Results from the FFS. Demographic Studies, 8(5), 107-150. doi: 10.4054/demres.2003.8.5

Ganong, L.H., \& Coleman, M. (2016). Stepfamily relationships: Development, dynamics, and intervention (2nd ed.). New York, NY: Springer. doi: 10.1007/978-1-4899-7702-1

Ganong, L.H., Coleman, M., \& Weaver, S. (2002). Relationship maintenance and enhancement in stepfamilies: Clinical applications. In J.H. Harvey \& A. Wenzel (Eds.), A clinician's guide to maintaining and enhancing close relationships (pp.105-129). Mahwah, NJ: Lawrence, Erlbaum Associates.

Gurman, A.S. (Ed.). (2008). Clinical handbook of couple therapy $\left(4^{\text {th }}\right.$ ed.). New York, NY: Guilford Press.

Hantrais, L., \& Letabiler, M.T. (2014). Families and family policies in Europe. NewYork, NY: Routledge.

Hardy, K.V., \& Laszloffy, T.A. (1995). The cultural genogram: Key to training culturally competent family therapists. Journal of Marital and Family Therapy, 21, 227-237. doi:10.1111/j.1752-0606.1995.tb00158.x

Hayes, A.F., \& Krippendorff, K. (2007). Answering the call for a standard reliability measure for coding data. Communication Methods and Measures, 1, 77-89. doi: 10.1080/ 19312450709336664

Hetherington, E.M., \& Stanley-Hagan, M. (2002). Parenting in divorced and remarried families. In M.H. Bornstein (Ed.), Handbook of parenting: Being and becoming a parent ( $2^{\text {nd }}$ ed., pp. 287-316). Mahwah, NJ: Lawrence Erlbaum Associates.

Higginbotham, B., \& Adler-Baeder, F. (2008). The Smarts Steps: Embrace the journey program: Enhancing relational skills and relationship quality in remarriages and stepfamilies. The Forum for Family and Consumer Issues, 13(3). Retrieved from: https://ncsu.edu/ffci/publications/2008/v13-n3-2008winter/higginbotham-adler.php

Higgs, J., Jones, M.A., Loftus, S., \& Christensen, N. (2008). Clinical reasoning in the health professions (3rd ed.). Amsterdam, NE: Elsevier (Butterworth Heinemann).

Hogan, B.E., Linden, W., \& Najarian, B. (2002). Social support interventions: Do they work? Clinical Psychology Review, 22(3), 383-442. doi:10.1016/s0272-7358(01)00102-7

ISTAT (2011). Come cambiano le forme famigliari [How family forms change]. Retrieved from: http://www.istat.it/it/files/ 2011/09/forme-familiari2009.pdf?title $=$ Come + cambiano + le+forme+familiari+-+ $15 \% 2$ Fset $\% 2$ F $2011+-+$ Testo+integrale.pdf

ISTAT (2015). Matrimoni, seperazioni e divorzi [Marriages, separations, and divorces]. Available from: http://www. istat.it/it/files/2015/11/Matrimoni-separazioni-e-divorzi2014.pdf?title=Matrimoni\%2C+separazioni $+\mathrm{e}+$ divorzi + +12\%2Fnov\%2F2015+-+Testo+integrale.pdf

Johnson, R.B., \& Onwuegbuzie, A.J. (2004). Mixed methods research: A research paradigm whose time has come. Educational Researcher, 33(7), 14-26.
Kreyenfeld, M., \& Heintz-Martin, V. (2011). The dynamics of stepfamilies cross-national perspective. Zeitschrift für Familienforschung, 23, 124-127.

Lancia, F. (2004). Strumenti per l'analisi dei testi. Introduzione all'uso di T-LAB [Instruments for text analysis. An introduction to the use of T-LAB]. Milan, Italy: FrancoAngeli.

Lewis, J.M., \& Kreider, R.M. (2015). Remarriage in the United States. American community survey reports. Retrieved from: http://www.census.gov/content/dam/Census/library/publications/2015/acs/acs-30.pdf

Livingston, G. (2014). Four-in-ten couples are saying "I do," again. Washington, DC: Pew Research Center.

Lord, C.G., Ross, L., \& Lepper M.R. (1979). Biased assimilation and attitude polarization: The effects of prior theories on subsequently considered evidence. Journal of Personality and Social Psychology, 37(11), 2098-2109.

Margola, D., Donato, S., Accordini, M., Emery, R.E., \& Snyder, D.K. (2017). Dyadic coping in couple therapy process: An exploratory study. Family Process. Advanced online publication. doi: 10.1111/famp.12304

Margola, D., Facchin, F., Morgola, S., \& Revenson, T.A. (2010). Cognitive and emotional processing through writing among adolescents who experienced the death of a classmate. Psychological Trauma: Theory, Research, Practice, and Policy, 2(3), 250-260. doi: 10.1037/a0019891

Mayring, P. (2000). Qualitative content analysis. Forum Qualitative Sozialforschung/Forum: Qualitative Social Research, 1(2), 20. Retrieved from: http://nbn-resolving.de/urn:nbn:de: 0114-fqs0002204

Mazzoni, S. (2002). Nuove costellazioni familiari: le famiglie ricomposte [New family constellations: Stepfamilies]. Milan, Italy: Giuffrè.

McDowell, T., Goessling, K., \& Melendez, T. (2012). Transformative learning through international immersion: Building multicultural competence in family therapy and counseling. Journal of Marital and Family Therapy, 38, 365-379. doi:10.1111/j.1752-0606.2010.00209.x

Morgan, D.L. (2007). Paradigms lost and pragmatism regained: Methodological implications of combining qualitative and quantitative methods. Journal of Mixed Methods Research, 1(1), 48-76. doi: 10.1177/2345678906292462

Papernow, P.L. (2015). Therapy with couples in stepfamilies. In J. Lebow, D. Snyder, \& A. Gurman (Eds.), The clinical handbook of couple therapy ( $5^{\text {th }}$ ed., pp. 467-488) New York, NY: Guilford Press.

Pasley, B.K., Koch, M., \& Ihinger-Tallman, M. (1994). Problems in remarriage: An exploratory study of intact and terminated remarriages. Journal of Divorce \& Remarriage, 20(1/2), 63-84. doi: 10.1300/j087v20n01_04

Pasley, B.K., Rhoden, J.L., Visher, E.B., \& Visher, J.S. (1996). Successful stepfamily therapy: Clients' perspectives. Journal of Marital and Family Therapy, 22, 319-333. doi: 10.1111/j.1752-0606.1996.tb00210.x

Pew Research Center (2011). A portrait of stepfamilies. Retrieved from: http://www.pewsocialtrends.org/2011/01/13/aportrait-of-stepfamilies/

Piercy, F.P., Chang, W., Palit, M., Chen, R., Karimi, H., Jaramillo-Sierra, A., ..., \& Antonio, A. (2014). A cross-national study of family therapy training: A collaborative pilot project. Contemporary Family Therapy, 36(2), 250-259. doi: 10.1007/s10591-014-9300-z

Price-Bonham, S., \& Balswick, J.O. (1980). The noninstitutions: Divorce, desertion, and remarriage. Journal of Marriage and the Family, 42(4), 959-972. doi: 10.2307/351835 
Rogers, J.C. (1983). Clinical reasoning: The ethics, science, and art. Eleanor Clarke Slagle lectureship. American Journal of Occupational Therapy, 37(9), 601-616.

Sprenkle, D.H., \& Blow, A.J. (2004). Common factors and our sacred models. Journal of Marital and Family Therapy, 30(2), 113-129. doi: 10.1111/j.1752-0606.2004.tb01228.x

Steinbach, A., Kuhnt, A.K., \& Knüll, M. (2016). The prevalence of single-parent and stepfamilies in Europe: Can the Hajnal line help us to describe regional patterns? The History of the Family, 21(4), 578-595. doi: 10.1080/1081602X. 2016.1224730

Stewart, S.D. (2005). Boundary ambiguity in stepfamilies. Journal of Family Issues, 26(7), 1002-1029. doi: 10.1177/ $0192513 \times 04273591$

U.S. Census Bureau (2012). 2012 National population projections. Retrieved from: http://www.census.gov/population/ projections/files/filelayout/NP2012_D1.pdf
Vetere, M. (Ed.). (2017). La sfida delle famiglie ricomposte. Un modello di intervento clinico. [The challenge of stepfamilies. A clinical intervention model]. Rome, Italy: Alpes.

Vikat, A., Spéder, Z., Beets, G., Billari, F., Bühler, C., Desesquelles, A., ..., Solaz, A. (2007). Generations and Gender Survey (GGS): Towards a better understanding of relationships and processes in the life course. Demographic Research, 17(14), 389-440. doi: 10.4054/demres.2007.17.14

Visher, E.B., \& Visher, J.S. (1988). Old loyalties, new ties: Therapeutic strategies with stepfamilies. New York, NY: Brunner/Mazel. doi: 10.4324/9781315803814

Visher, E.B., \& Visher, J.S. (1996). Therapy with stepfamilies. New York, NY: Brunner/Mazel.

Visher, E.B., \& Visher, J.S. (1998). Stepparents: The forgotten family members. Family \& Conciliation Courts Review, 36(4), 444-451. doi: 10.1111/j.174-1617.1998.tb01089.x 